\title{
Short-Beam Three-Point Bend Tests in Syntactic Foams. Part II: Effect of Microballoons Content on Shear Strength
}

\author{
Kishore, ${ }^{1}$ Ravi Shankar, ${ }^{2}$ S. Sankaran ${ }^{3}$ \\ ${ }^{1}$ Polymer Composites Laboratory, Department of Metallurgy, Centre for Advanced Studies, Indian Institute of Science, \\ Bangalore-560 012, India \\ ${ }^{2}$ Department of Material Science and Engineering, North Carolina State University, Raleigh, \\ North Carolina 27695-7907 \\ ${ }^{3}$ Aeronautical Development Establishment, C. V. Raman Nagar, Bangalore-560 093, India
}

\begin{abstract}
Epoxy binders containing microballoons ranging from 38.5 to $57.7 \%$ by volume were cast in a mold and cured, and the resulting slabs were sectioned to yield short-beam test coupons. The strength changes with microballoons content were noted. These reveal an increase from 3.87 to $5.79 \mathrm{MPa}$ for a decrease in microballoons content from 57.7 to $38.5 \%$. Mechanical data were correlated with fractographic features employing scanning electron micro-
\end{abstract}

scope. The failure features involving the microballoons and interface regions are highlighted in this article. The works show the existence of a dependence of strength parameters on the inter-microballoon distances. (C) 2005 Wiley Periodicals, Inc. J Appl Polym Sci 98: 680-686, 2005

Key words: composites; shear; microballoons content; SBT strength; density

\section{INTRODUCTION}

Polymer composite materials perform quite well in very many test conditions like tension, compression, impact, flexural, torsion, etc. Their growth over the years, as end products catering to many engineering applications, has been impressive. Other favorable factors, such as polymer, displaying a wide range of properties, and the ease with which desired properties can be achieved by tailoring the systems, have contributed to this growth considerably. Polymer composites having reinforcements of either particulates or fibers are commonly employed. It is well known that the mechanical behavior of polymer systems is strongly influenced by factors such as type, size, content, and shape of the reinforcements. The treatments given to surfaces of the reinforcement also add to this variability factor. It is noticed from the published literature that the effects of filler content on the mechanical properties such as tension, compression, impact, flexural, fracture toughness, and fatigue have been studied in detail. ${ }^{1-12}$

Thus, Herrera-Franco et al. ${ }^{1}$ studied an unusual combination involving high-density polyethylene (HDPE) with sand and natural fibers (henequen). For HDPE-sand composite, at filler content $<15 \% \mathrm{w} / \mathrm{w}$, the processing temperatures had an important bearing on the tensile modulus. Flexural strength, on the other hand, showed a maximum at filler content of $30 \%$ $\mathrm{w} / \mathrm{w}$. As regards the flexural modulus, it increased linearly ${ }^{1}$ with filler for both HDPE-sand and HDPEhenequen composites. In another effort, both the amount of filler and the effect of silane-coupling agent (surface treatment) on the tensile properties of glassbead-filled polypropylene composites were studied and the report showed that Young's modulus $\left(E_{C}\right)$ increased nonlinearly with increasing volume ( $\mathrm{vol}$ ) fraction of glass beads, in the range $0-30 \%{ }^{2}$ The $d y-$ namic properties of epoxy composites filled with quartz powder were also found to increase when a tension-compression device was employed by Goyanes et al. ${ }^{3}$ Otaigbe and Adams ${ }^{4}$ focused on bioabsorbable soy protein plastics composites and found improvements in stiffness, strength, and water resistance with increasing polyphosphate filler content up to $20 \%$ by weight. ${ }^{4}$ The dependence of mechanical properties such as strength, modulus, and fracture toughness on the volume fraction of the reinforcing glass fibers and glass beads in poly(oxymethylene) matrix forms the topic of another study. ${ }^{5}$ The majority of the parameters looked into in this work ${ }^{5}$ seemed to be linear functions of the volume fraction of the fibers or the glass beads. In another work, Maiti and Mahapatro $^{6}$ studied the tensile and flexural properties as well as the impact behavior of nickel-powder-filled polypropylene composites in the composition range $0-3.5 \mathrm{vol} \% \mathrm{Ni}^{6}{ }^{6}$ Izod impact strength at first increased up to a critical $\mathrm{Ni}$ content beyond which the value 
TABLE I

Densities of Constituent Materials for Syntactic Foam

\begin{tabular}{lc}
\hline \multicolumn{1}{c}{ Materials } & $\begin{array}{c}\text { Bulk Density } \\
\left(\mathrm{kg} / \mathrm{m}^{3}\right)\end{array}$ \\
\hline $\begin{array}{l}\text { Microspheres } \\
\text { Epoxy (LY-556)/hardener (HT-972) }\end{array}$ & 250 \\
\hline
\end{tabular}

decreased inappreciably, whereas flexural modulus and strength increased with filler concentration. ${ }^{6}$ The effect of the presence of filler of differing aspect ratios in the form of short fibers and particulate fillers on fatigue crack propagation (FCP) in polyamides has also been reported. ${ }^{7}$ The FCP resistance was found to increase with increasing fiber content and interfacial adhesion for nylon $66 .^{7}$

Although from the published literature it can be seen that, generally stated, with an increase of filler content, the mechanical properties increase, some data also show a reversal of trends. In literature, work on polyethylene-polyaniline polymer-polymer composites is cited, where, as the concentration of the conducting polymer in the blend is raised, tensile strength and elongation at break were found to decrease. ${ }^{8}$ To observe the effect of filler content on particulate biphasic calcium phosphate-polyactide composites, Bleach et al. ${ }^{9}$ carried out both static as well as dynamic tests. As the filler content increased, the failure strain decreased due to a reduction in the amount of ductile polymer present. ${ }^{9}$ The decrement in ultimate tensile strength was due to particle agglomeration and void formation at higher filler content. ${ }^{9}$ In another work, by using instrumented impact tests, the dynamic response of particulate-filled polymer composites was studied. ${ }^{10}$ The work $^{10}$ showed that increasing the $\mathrm{CaCO}_{3}$ content in $\mathrm{CaCO}_{3} / \mathrm{HDPE}$ composites decreases the impact resistance. ${ }^{10}$ Goyanes et al. ${ }^{11}$ studied the influence of the aluminum powder (filler) content in epoxy resin composite by considering compressive tests at room temperature at different strain rates. The compressive yield stress was found to decrease by increasing the aluminum at a constant strain rate and for filler volume fractions higher than $0.10 \%{ }^{11}$

From the published literature, cited hitherto, it is noticed that the mechanical properties, depending upon the filler content, either increase or decrease. However, when newer parameters, related to other physical or mechanical aspects, of some of the above cited works ${ }^{1-11}$ are looked into, it is noticed that the effect of filler content on properties depend on the exact property under consideration.

Instead of restricting to notice the variations in flexural strength and flexural modulus, when the work was extended to evaluating the tensile strength of HDPE-sand composites, Herrera-Franco et al. ${ }^{1}$ no-
TABLE II

Details of Fabricated Syntactic Foam Slabs

\begin{tabular}{cccc}
\hline $\begin{array}{c}\text { Foam } \\
\text { designation }\end{array}$ & $\begin{array}{c}\text { Volume \% of } \\
\text { microballoons }\end{array}$ & $\begin{array}{c}\text { Density of the } \\
\text { cast slab } \\
\left(\mathrm{kg} / \mathrm{m}^{3}\right)\end{array}$ & $\begin{array}{c}\text { Strength in short } \\
\text { beam test }(\mathrm{MPa})\end{array}$ \\
\hline Slab 4 & 38.5 & 827.5 & 5.79 \\
Slab 3 & 50.2 & 722.5 & 4.77 \\
Slab 2 & 54.5 & 680.0 & 4.05 \\
Slab 1 & 57.7 & 648.8 & 3.87 \\
\hline
\end{tabular}

ticed a decrease with filler content. Similarly, Liang and $\mathrm{Li}^{2}$ found that the tensile yield strength $\left(\sigma_{y c}\right)$ and tensile stress at break $\left(\sigma_{b c}\right)$ of the composite decrease with the increase in volume fraction values for glass beads in the range $0-30 \%$.

Besides the filler content, mechanical properties also depend on the type of fillers used with the matrix. $3,8,10,11$ Thus, instead of glass beads or glass fibers, if a hollow microballoon form of glass material is used, its presence should influence the resultant properties of the composite material. However, from the published literature, it is found that reports correlating microballoons content with strength values are scarce, more so for the short-beam test conditions.

Aforementioned published literature, thus, clearly establishes the fact that the filler content has noticeable effects on the mechanical properties of the polymer composites but they do not follow a general trend. Depending upon the mechanical properties under investigation in the experiment, they display an increase or a decrease with filler levels. ${ }^{1,2}$ Also obvious from the above coverage of the polymer-filled systems literature is the fact that an evaluation of shear strength

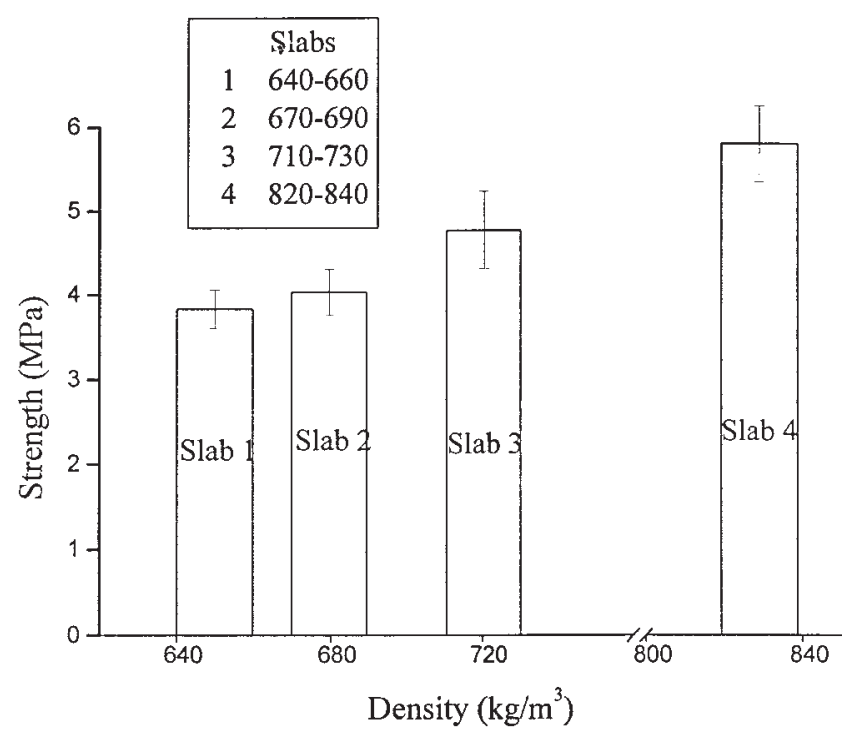

Figure 1 A histogram showing the decrease in strength from slabs 4 to 1 (i.e., of decreasing density). 


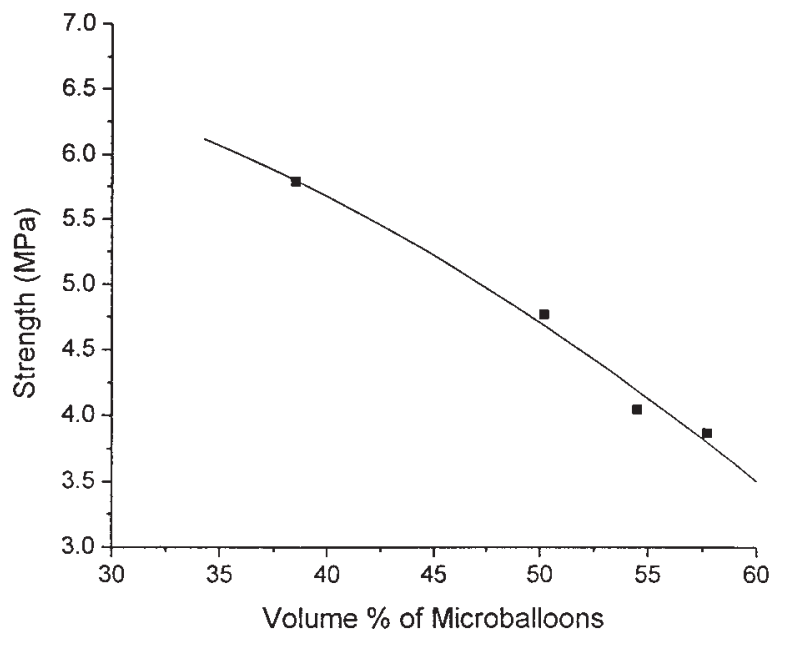

(a)

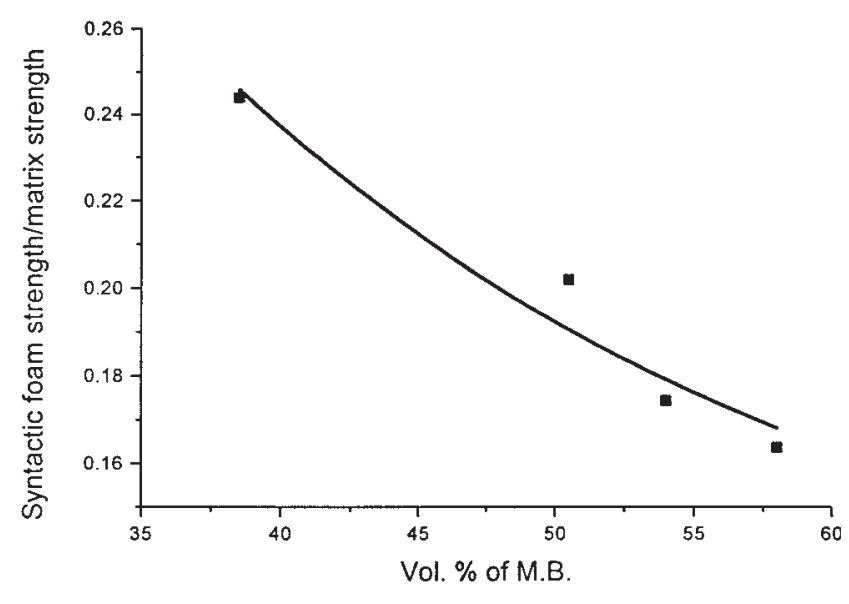

(b)

Figure 2 Trends in strength with microballoons content for (a) as tested syntactic foams and (b) normalized case bringing in the matrix strength.

is given a low priority as compared to other mechanical properties.

To evaluate this less explored shear-related experimental parameter, different testing methods like lap shear, double lap shear, ${ }^{12}$ butt, torsion, and compression shear tests ${ }^{13}$ exist. A greater part of such efforts has seen the data being generated by three-point bend (short beam) tests. ${ }^{14-20}$ Thus, the effects of interface control and matrix microstructure on the interlaminar shear strength and mode II interlaminar fracture toughness of $5 \mathrm{H}$ satin woven $\mathrm{C} / \mathrm{C}$ composites were investigated by Hojo et al. ${ }^{14}$ by three-point short-beam flexure tests. Blackketter et al. ${ }^{15}$ studied the evaluation of fiber surface treatment and sizing on the shear and transverse tensile strengths of carbon fiber-reinforced thermoset and thermoplastic matrix composites. Cui et al. ${ }^{19}$ studied the failure mechanism in the three- and four-point bending tests. The short beam shear and interlaminar shear tests are compared as methods of determining interlaminar shear strength of thermoplastic composite rings by Rosselli and Santare. ${ }^{20}$ Shear strength studied so far has been limited to narrow ranges such as comparison of different shear tests parameter, and further towards noting the effect of processing variations like surface treatment of the fillers on the shear strength. It is therefore important to study the dependence of this parameter on the filler content so that a better design of the components can be made, which can extend their service life.

Published reports, which are fewer in number for syntactic foams, become even scarcer when a search for a microballoons-filled system concerning the shear-related properties is conducted. Thus, with regards to glass hollow microballoons-filled epoxy, known as syntactic foams, the available reports on the evaluation of this parameter are mentioned in only a few publications. ${ }^{21-23}$ Further, as regards the core materials (used in structural sandwich structures), only limited reference is available. ${ }^{24}$ Thus, reports of threepoint bending (TPB) test on PVC foam show that core shear behavior is better represented by TPB, whereas ISO 1922 specification is unsuitable to correctly measure the core shear strength. ${ }^{24}$ Another key factor evident from a perusal of the published material is the fact that no reports are available on the effect of variation of microballoons content on the strength of the syntactic foam in short-beam test conditions. Therefore, to fill the gap that exists in the literature, the present effort, for the first time, looks at the effect of microballoons content on the shear strength of the syntactic foams by short-beam three-point bend (SBT) test. While doing so, the information gathered from the scanning electron microscope (SEM) examination from the earlier part (i.e., Part I) ${ }^{25}$ will be made use of and the structural variations with respect to filler content and its effect on strength, in the short beam tests, will be looked into.

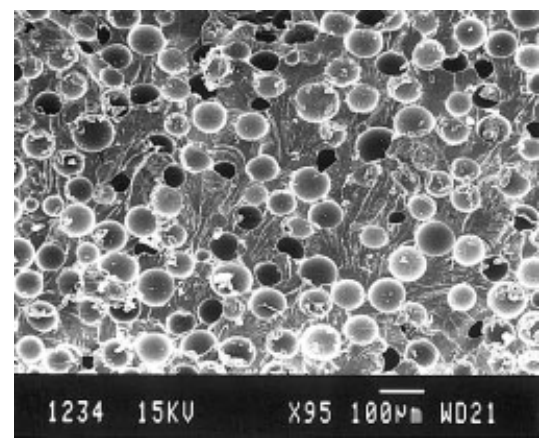

Figure 3 Low-magnification macropicture of a sample (i.e., slab 1) displaying the maximum amount (i.e., $57.7 \%$ ) of microballoons. 


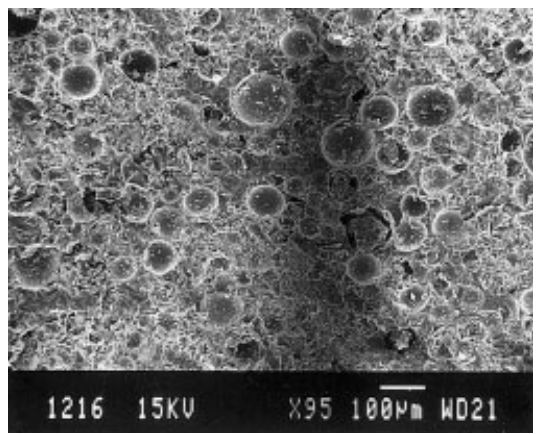

Figure 4 The distribution of microballoons in another sample having $54.5 \mathrm{vol} \%$ of microballoons (slab 2).

\section{MATERIALS}

All the syntactic foams employed in this study were prepared by using epoxy matrix consisting of Araldite LY-556 (bisphenol-A diglycidyl ether) and Hardener HT-972 (aromatic amine) having resin to hardener ratio of $100: 27$ by weight. Epoxy resin having an epoxy equivalent weight value of 190, as specified by the manufacturer, is supplied by Vantico Performance Polymers Pvt. Ltd. (Mumbai, India). The density of the cured resin system was $1180 \mathrm{~kg} / \mathrm{m}^{3}$. Glass hollow microspheres (called glass microballoons), Ecospheres SI (supplied by Grace Electronic Materials, Westerlo, Belgium), constitute the filler material. Density of the glass microballoons is $250 \mathrm{~kg} / \mathrm{m}^{3}$. Microballoons, used here, were chosen in the narrow diameter range of 75-90 $\mu \mathrm{m}$ for making the two-phase syntactic foams unlike the earlier section (i.e., Part $\mathrm{I}^{25}$ ), where they had a size range of $44-175 \mu \mathrm{m}$. Details of the constituents used in making syntactic foams are given in Table I.

\section{Materials processing}

Syntactic foam slabs were processed by varying the volume fraction of resin and microballoons. Weighed quantity of resin was heated in a beaker to $95^{\circ} \mathrm{C}$ upon which microballoons were added in small lots. The slurry, which, depending upon microballoons propor-

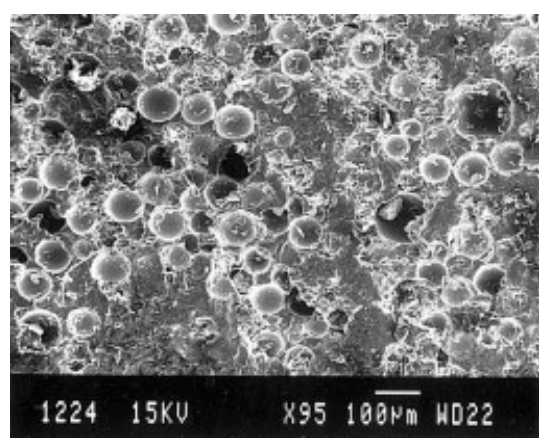

Figure 5 A sample (slab 3) with 50.2 vol \% microballoons.

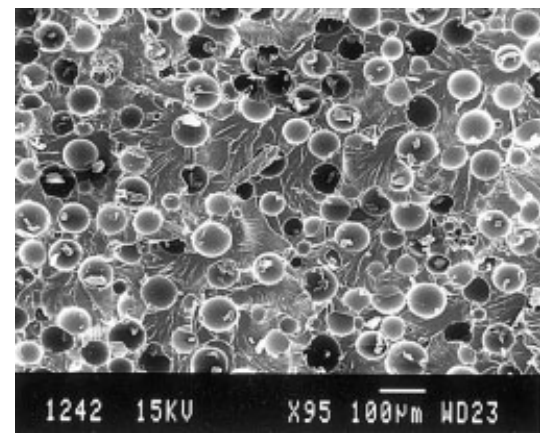

Figure 6 Shear deformation bands on the matrix seen on the least microballoons (38.5\%) bearing cast and cured slab (i.e., slab 4).

tion could result in dough formation, was filled into a metallic mold with dimensions of $150 \times 150 \times 25 \mathrm{~mm}$. Curing cycle employed is same as listed in our previous article. ${ }^{25}$ Briefly stated, it is cured at room temperature for $24 \mathrm{~h}$, then cured first at $100^{\circ} \mathrm{C}$ for $4 \mathrm{~h}$ followed by postcuring at $160^{\circ} \mathrm{C}$ for $3 \mathrm{~h}$. Burn-out test at $650^{\circ} \mathrm{C}$ for $4 \mathrm{~h}$ was done for the failed short-beam test samples to determine the exact amount of the microballoons present in each of the specimens. The data were useful in knowing the actual microballoons content and hence in precisely determining the role of microballoons in influencing SBT strength value. Details of the compositions of the four different syntactic foams slabs, labeled slabs 4 to 1 , are listed in ascending order of vol \% for microballoons in Table II.

\section{Short-beam three-point bend tests}

Short-beam three-point loading tests for this series of experiments were carried out on a MTS 810 model machine. The machine was programmed to apply the load at a constant crosshead rate of $1.3 \mathrm{~mm} / \mathrm{min}$. Tests were performed on samples having dimensions of 3 $\times 15 \times 21 \mathrm{~mm}$ and conforming to the ratio $1: 5: 7$ for thickness: span length: total length. Five samples

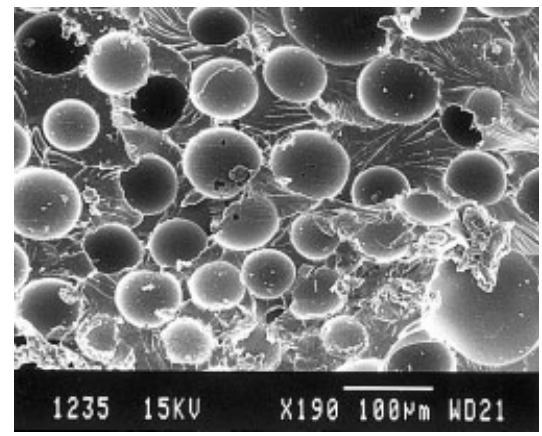

Figure 7 A higher magnification micrograph of the failed sample belonging to slab 1 . 


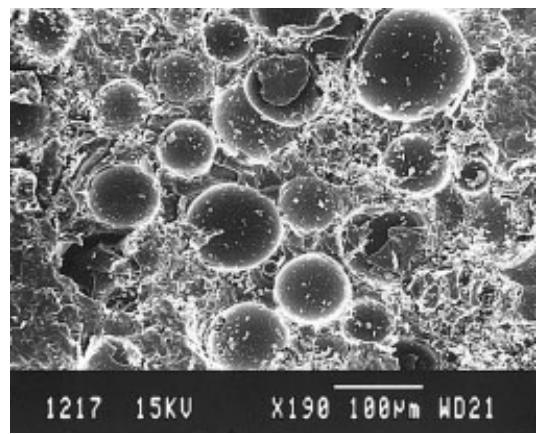

Figure 8 A higher magnification micrograph of the failed sample belonging to slab 2 having 54.5\% microballoons.

were made and tested for the four different cast slabs (Table II).

\section{Microscopy}

The failed samples from SBT were mounted in a JEOL JSM 840A SEM to observe the fracture surface. Gold coating was done in a sputtering unit at a current of 10 $\mathrm{mA}$ on the test samples before examining in the SEM.

\section{RESULTS AND DISCUSSION}

Table II lists the average strength values obtained by employing five samples for each of the four different slabs cast. A scatter in the values recorded during experimentation and corresponding to each type of the slabs is shown in Figure 1, where the slabs are grouped as per the densities exhibited by each one (shown in the inset in Fig. 1). Observing the overall values, a general feature that draws immediate attention is the fact that, compared to the thermoset polymer composites reinforced generally with glass fibers, ${ }^{26,27}$ the strength values recorded for this system are on the lower side. This difference arises partly from the aspect ratio of fibers in fiber-reinforced composites being high, whereas glass microballoons-reinforced composites have this value, which is nearer to unity. Second, the surface area for a given volume level of reinforcement is not the same in the two cases. Also, the directionality properties that a fiber induces in the fibrous composite system is important. Although this situation could be favorable to the microballoons bearing system under certain loading situations, where the isotropic properties are desired, it may not yield desired results in other loading conditions, as a crack originating at one microballoons/ matrix interface may find it easier to propagate to the next one with considerable ease, making the response of the system different from those having basically fibers as reinforcement. Therefore, it is important to study the properties of such matrix/filler interface in syntactic foams. This is best done through microscopy, especially on post-SBT failed samples. These data are presented, therefore, in the latter part of this article. Before elaborating on the microscopy, it is evident from Table II that as the volume percent of the microballoons decrease from slab 1 to slab 4, density as well as short beam test strength increases. Figure 2(a) graphically shows how, as the volume \% of microballoons increases from 38.5 to $57.7 \%$, there is a decrease in SBT strength. To ascertain the true effect of reinforcement (i.e., microballoons) on composite (syntactic foam) strength, data in Figure 2(a) are plotted again in Figure 2(b), this time as a ratio of syntactic foam strength to matrix strength varying the volume $\%$ of microballoons in the composite. This also depicts a downward trend earlier emphasized while discussing the details of Figure 2(a). This finding is in accordance with the study on rigid polyurethane (PUR) foam, ${ }^{28}$ where it has been shown that the fracture stress under shear loading increases with the density of the foam. Similar behavior is also observed in the case of rigid poly(vinyl chloride) (PVC) foam. ${ }^{28}$ The increase in the strength, however, is much higher in the PVC case compared to that noticed with PUR rigid foams. The present results on the short-beam three-point bend tests indicate that strength is directly related to the amount of the microballoons in the syntactic foams. Although inherently glass is harder than epoxy, owing to the fact that glass microballoons are hollow in nature, they offer less resistance compared to when solid glass spheres are embedded in the same system. The increase in strength with a decrease in the microballoons content in the slab can be correlated to the features noted by microscopy done on the fractured samples. Thus, Figures 3-6 are the lower magnification micrographs of the test-failed samples of slabs 1 to 4 having 57.7, 54.5, 50.2, and 38.5 vol \% of microballoons, respectively. Among these micrographs, Figure 3 has the maximum number of microballoons (i.e., slab 1) displaying the least of SBT strength. On the other hand, Figure 6, having maximum strength, has the least of microballoon dispersions. Thus, there is a oneto-one correlation between microstructural features

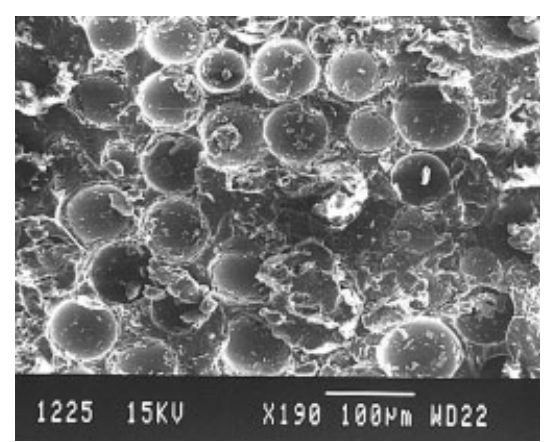

Figure 9 A higher magnification micrograph of the failed sample belonging to slab 3 . 


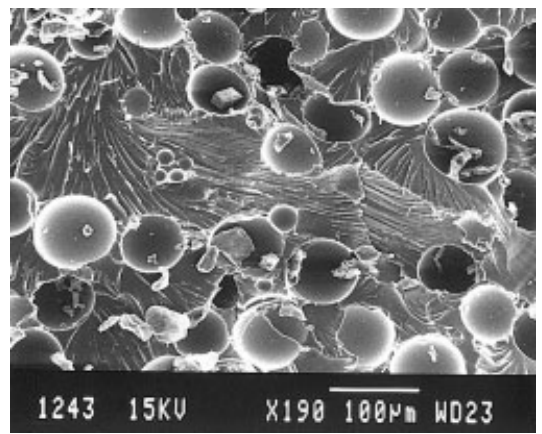

Figure 10 The flow pattern showing the shear deformation bands for the lowest vol \% (i.e., 38.5\% microballoons) bearing slab 4.

and strength data recording. To correlate the mechanical data with microscopic features better, further microscopic examination, this time at a slightly higher magnification, was done and the resulting efforts are presented in Figures 7-10. Figure 10 shows extensive shear deformation bands, for the specimen displaying highest SBT strength. Figure 7, taken on a sample that shows the least strength, on the other hand, has lesser of the matrix deformation features. To emphasize the role of interface, the microscopy was done at still higher magnification. Figure 11 is the micrograph of the slab having $38.5 \mathrm{vol} \%$ of microballoons and having maximum strength. This shows the extensive deformation bands between the two microballoons represented by A and B at the diagonal corners. Between the two, and well outlined on the matrix system, are the curvilinear features of deformation bands indicating resistance offered by the dispersed microballoons. Of interest to note is the fact that there is a flow of matrix over the lower microballoon, marked by arrows. Thus, in this level of microballoons-bearing system, the situations at the interfacial regions promote better resistance to deformation process. Also, obvious is the fact that this composition (38.5\% microballoons of slab 4) exhibits the largest inter-microballoons dis-

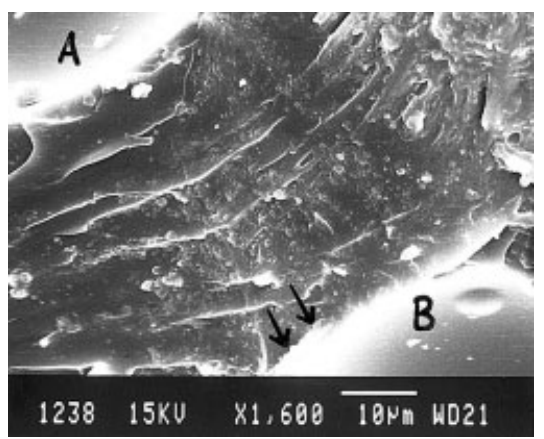

Figure 11 The matrix sandwiched between two larger microballoons bearing sample (38.5\% microballoons i.e., slab 4) showing clear and regular deformation bands.

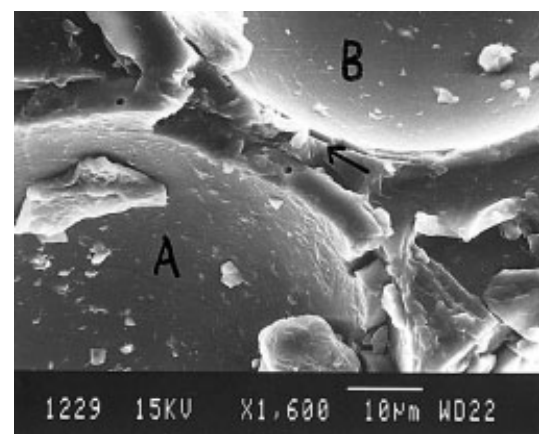

Figure 12 A high-magnification micrograph showing as to how the matrix responds to deformation when inter-microballoons (marked A and B) distance is small. Note the lack of matrix support to accommodate deformation and the attendant defects that spread on the lower right part.

tance among the four slabs investigated in this work. To examine what the features would be like, when inter-microballoons distances are small, a higher microballoon (i.e., 54.5\%) case is presented in Figure 12. This shows less resistance offered by the sandwiched matrix between the two microballoons (again seen at diagonal corners), owing to the less matrix material available to accommodate such a process of shear flow. Debonding of the microballoons, marked by an arrow, occurs and this facilitates crack growth. One such crack is shown by an arrow at B. It is well known that such fissures trigger early failure, and, hence, lower strength results as compared to the specimens having larger inter-microballoons distance shown in Figure 11 . Thus the work clearly shows inter-microballoons distance (occupied by matrix) govern the SBT test values: the smaller this distance, the lower the strength and vice versa.

\section{CONCLUSIONS}

It is evident from this work that as the volume percent of the microballoons decreases, density of the foam as well as failure strength in short-beam shear test increases. Syntactic foam having the least microballoons content and having the largest inter-microballoons spacing displays extensive matrix deformation.

\section{References}

1. Herrera-Franco, P. A.; Valadez-Gonzalez, M.; Cervantes-Uc. Compos Part B Eng 1997, 28, 331.

2. Liang, J. Z.; Li, R. K. Y. Polym Intl 2000, 49, 170.

3. Goyanes, S. N.; Marconi, J. D.; Koing, P. G.; Martin, M. D.; Mondragon, I. J Alloy Compd 2000, 28, 374.

4. Otaigbe, J. U.; Adams, D. O. J Environ Polym Degrad 1997, 5, 199.

5. Hashemi, S.; Gilbride, M. T.; Hodgkinson, J. J Mater Sci 1996, 31, 5017.

6. Maiti, S. N.; Mahapatro, P. K. Polym Compos 1992, $13,47$. 
7. Lang, R. W.; Manson, J. A.; Hertzberg, R. W. Polym Eng Sci 1981, 22, 982.

8. Chipara, M.; Hui, D.; Notingher, P. V.; Chipara, M. D.; Lau, K. T.; Sankar; Panaitescu, J. D. Compos Part B Eng 2003, 34, 637.

9. Bleach, N. C.; Nazhat, S. N.; Tanner, K. E.; Kellomski, M.; Tormala, P. Biomaterials 2002, 23, 1579.

10. Suwanprateeb, J. Polym Plast Technol Eng 2000, 39, 83.

11. Goyanes, S.; Rubiolo, G.; Marzocca, A.; Salgueiro, W.; Somoza, A.; Consolati, G.; Mondragon, I. Polymer 2003, 44, 3193.

12. Pahr, D. H.; Rammerstorfer, F. G.; Rosenkranz, P.; Humer, K.; Weber, H. W. Compos Part B Eng 2002, 33, 123.

13. Schneider, K.; Lauke, B.; Beckert, W. Appl Compos Mater 2001, 8,43 .

14. Hojo, M.; Yamao, T.; Tanaka, M.; Ochiai, S.; Iwashita, N.; Sawada, Y. Mater Sci Res Intl 2001, 7, 34.

15. Blackketter, D. M.; Upadhyaya, D.; King, T. R.; King, J. A. Polym Compos 1993, 14, 430

16. Duvis, T.; Papaspyrides, C. D. Polym Adv Technol 1994, 5, 444.
17. Daniels, B. K.; Harakas, K. N.; Jackson, R. C. Fiber Sci Technol 1971, 3, 187.

18. Dufort; Drapier, S.; Grediac, M. Compos Part A 2001, 52, 233.

19. Cui, W. C.; Wodnom, M. R.; Jones, M. J Strain Anal Eng Des 1992, 27, 235.

20. Rosselli, F.; Santare, M. H. Compos Part A 1997, 28, 587.

21. Lorenzeo, B.; Francesco, G. Solid Struct 2001, 38, 307.

22. Gupta, N.; Woldesenbet, E.; Kishore; Sankaran, S. J Sandw Struct Mater 2002, 4, 249.

23. Palumbo, M.; Tempesti, E. Appl Compos Mater 2001, 8, 343.

24. Capringo, G.; Langella, A. J Compos Mater 2000, 34, 791.

25. Kishore; Shankar, R; Sankaran, S., J Appl Polym Sci, to appear.

26. Hoecker, F.; Karger-Kocsis, J. Composite 1994, 25, 729.

27. Fischer, S.; Rosensaft, M.; Marom, G. Compos Sci Technol 1986, $25,69$.

28. Menges, G.; Knipschild, F. in Mechanics of Cellular Plastics; Hilyard, N. C., Ed.; Applied Science Publishers: Essex, UK, 1982; Chapter 2A, p 67. 